MATEC Web of Conferences 19,01022 (2014)

DOI: $10.1051 /$ matecconf/ 20141901022

C Owned by the authors, published by EDP Sciences, 2014

\title{
Comprehensive definition of thermal losses taking into account to the conditions of thermal networks
}

\author{
Yuliia S. Tsygankova, Margarita A. Dmitrienko \\ National Research Tomsk Polytechnic University, 634050 Tomsk, Russia
}

\begin{abstract}
The article presents an analytical evaluation of heat losses through the thermal insulation of pipelines, taking into account the actual operating conditions of thermal networks. Calculations confirmed a significant influence of the main operational factors on the increase in heat loss and the possibility of energy saving in heating networks.
\end{abstract}

\section{Introduction}

Now the considerable attention is given to a problem of savings of power resources [1]. A necessary condition of economically effective work of thermal networks is decrease in unproductive transport losses of heat through the isolated designs of pipelines.

While in service there can be situations when some sites of pipelines have the humidified, deformed or destroyed thermal isolation. of operation of a heating main (flooding of channels rain, soil or thawed snow, accidents in heat supply and water removal system, sharp temperature drops of environment, long operation and isolation ageing). In these conditions actual value of factor of heat conductivity of isolation of the pipeline differs from help value [2]. The known analytical way of definition of thermal losses [2] does not consider influence of the listed factors and, accordingly, leads to insufficiently exact calculation of transport thermal losses.

Therefore working out of tools for operative revealing of the high thermal losses allowing as more as possible precisely to define loss in a thermal network, not conducting expensive tests [3], is actual.

The purpose of this work is creation of the analytical tool for an estimation of losses of heat considering not only geometrical characteristics and ways of a lining of pipelines, but also influence of supernumerary conditions of operation and a real technical condition of isolation on change of thermal losses.

\section{Problem statement}

Testing of the developed method is spent on an example of a fragment of a typical two-trumpet thermal network of Mariinsk (Figure 1). Characteristics of sites and typical conditions of their operation are presented to tab. 1. Isolation type - mineral cotton wool, a way of a lining - underground in the channel not through passage. Initial climatic data [4]: the temperature of external air is equal $273 \mathrm{~K}$, the average temperature of a ground on depth of $8 \mathrm{~m}$ is equal $278 \mathrm{~K}$, the temperature of direct network water is equal 363 $\mathrm{K}$, the temperature of return network water is equal $323 \mathrm{~K}$.

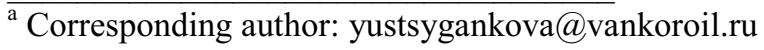

This is an Open Access article distributed under the terms of the Creative Commons Attribution License 4.0, which permits unrestricted use, distribution, and reproduction in any medium, provided the original work is properly cited. 


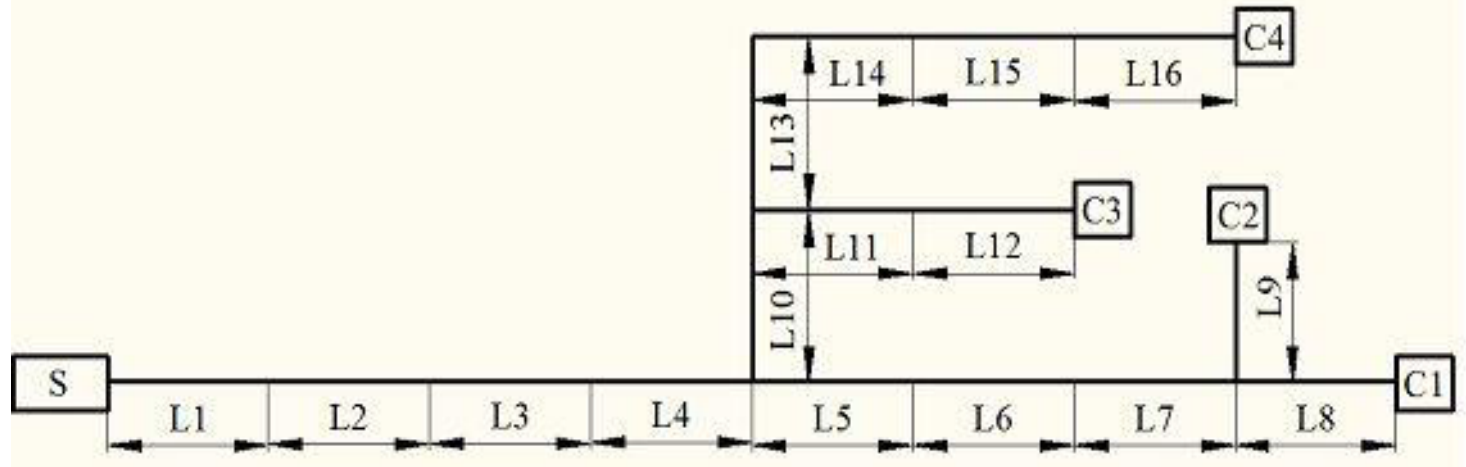

Figure 1. Fragment of a thermal network: L1 - L6 - sities of a thermal network with various conditions of operation and an isolation condition, $\mathrm{S}$ - thermal sourse, $\mathrm{C} 1-\mathrm{C} 4$ - heat consumers № 1-4.

Table 1. Sites characteristics of a thermal network

\begin{tabular}{|c|c|c|c|l|}
\hline $\begin{array}{c}\text { № } \\
\text { site }\end{array}$ & Length, $\mathrm{m}$ & $\begin{array}{c}\text { Conditional } \\
\text { diameter, } \mathrm{mm}\end{array}$ & $\begin{array}{c}\text { External diame- } \\
\text { ter of isolation, } \\
\mathrm{mm}\end{array}$ & \multicolumn{1}{|c|}{$\begin{array}{c}\text { Conditions of operation and an isola- } \\
\text { tion condition }\end{array}$} \\
\hline 1 & 1700 & 400 & 560 & Design conditions \\
\hline 2 & 300 & 400 & 560 & Isolation is humidified on $50 \%$ \\
\hline 3 & 150 & 400 & 560 & Isolation is humidified on $70 \%$ \\
\hline 4 & 200 & 400 & 560 & Isolation is humidified on $100 \%$ \\
\hline 5 & 230 & 300 & 450 & Isolation is humidified on $100 \%$ \\
\hline 6 & 1240 & 300 & 450 & Design conditions \\
\hline 7 & 440 & 300 & 450 & Damp air in the channel \\
\hline 8 & 100 & 50 & 125 & Isolation is absent \\
\hline 9 & 100 & 150 & 250 & Isolation is deformed \\
\hline 10 & 510 & 250 & 400 & Damp air in the channel \\
\hline 11 & 250 & 100 & 180 & Isolation is humidified on $10 \%$ \\
\hline 12 & 390 & 100 & 180 & Design conditions \\
\hline 13 & 310 & 100 & 180 & Isolation is humidified on $40 \%$ \\
\hline 14 & 100 & 100 & 180 & Isolation is absent \\
\hline 15 & 180 & 100 & 180 & Isolation is deformed \\
\hline 16 & 420 & 100 & 180 & Design conditions \\
\hline
\end{tabular}

The problem of definition of heat losses for a thermal network (fig. 1) is solved at following assumptions:

heat technical characteristics of substances are constant and known sizes. In a considered range of change of the basic influencing parametres (temperature, pressure) heat technical properties of substances change slightly $[2,5]$ and this change can be neglected;

- thermal resistance of walls of pipelines and the channel is not considered. Their thermal resistance much less than thermal resistance of the insulation layer [6];

- heat-carrier leaks are absent.

The basic engineering formulas used for the account of influence of negative factors (tab. 1), are presented in [7]. In this case for the purpose of optimisation of calculations for definition of thermal losses earlier developed and registered program complex [8] is used. The program allows to define losses of thermal energy and heat-carrier temperature drop on length of pipelines for any configuration of thermal networks. The step-by-step calculation of specific thermal losses realised in the program allows to recal- 
culate on each individual site of a heating main a variable on length air temperature in the channel and to consider change of factor of thermal return in the course of heat-carrier cooling.

Comparison of the thermal losses calculated in a program complex [8] with the losses received on the basis of natural tests on concrete sites of a thermal network, show convergence of results comprehensible to practice [9].

\section{Results and conclusion}

Values of the thermal losses calculated taking into account a condition of isolation and conditions of operation of heat conductors $\left(\mathrm{Q}_{\text {cal. }}\right)$, are resulted in tab. 2 and on fig. 2. For comparison and the analysis of the received results in tab. 2 and on fig. 2 the losses defined by an official technique [2] - $Q_{d .}$ and standard losses of heat - $Q_{\text {norm. }}[10]$.

Table 2. The results of definition of transport thermal losses

\begin{tabular}{|c|c|c|c|c|c|c|}
\hline \multirow{2}{*}{$\begin{array}{c}\text { Heat } \\
\text { consumer }\end{array}$} & \multirow{2}{*}{ Length, $\mathrm{m}$} & \multicolumn{3}{|c|}{ Thermal losses, $\mathrm{kWt}$} & \multirow{2}{*}{$\left(\mathrm{Q}_{\text {cal. }}-\mathrm{Q}_{\mathrm{d} .}\right) / \mathrm{Q}_{\mathrm{d} .}}$, & \multirow{2}{*}{$\begin{array}{c}\left(\mathrm{Q}_{\text {norm. }}-\mathrm{Q}_{\mathrm{d} .}\right) / \mathrm{Q}_{\mathrm{d} .}, \\
\%\end{array}$} \\
\cline { 3 - 6 } & $\mathrm{Q}_{\text {cal. }}$ & $\mathrm{Q}_{\mathrm{d} .}$ & $\mathrm{Q}_{\text {norm. }}$ & & 42 \\
\hline $\mathrm{C} 1$ & 5160 & 847.3 & 331.9 & 472.7 & 155 & 43 \\
\hline $\mathrm{C} 2$ & 5160 & 830.7 & 332 & 475 & 150 & 37 \\
\hline $\mathrm{C} 3$ & 4300 & 701.7 & 276.5 & 378.9 & 154 & 37 \\
\hline $\mathrm{C} 4$ & 4670 & 763.3 & 289.7 & 397.5 & 163 & 42 \\
\hline
\end{tabular}

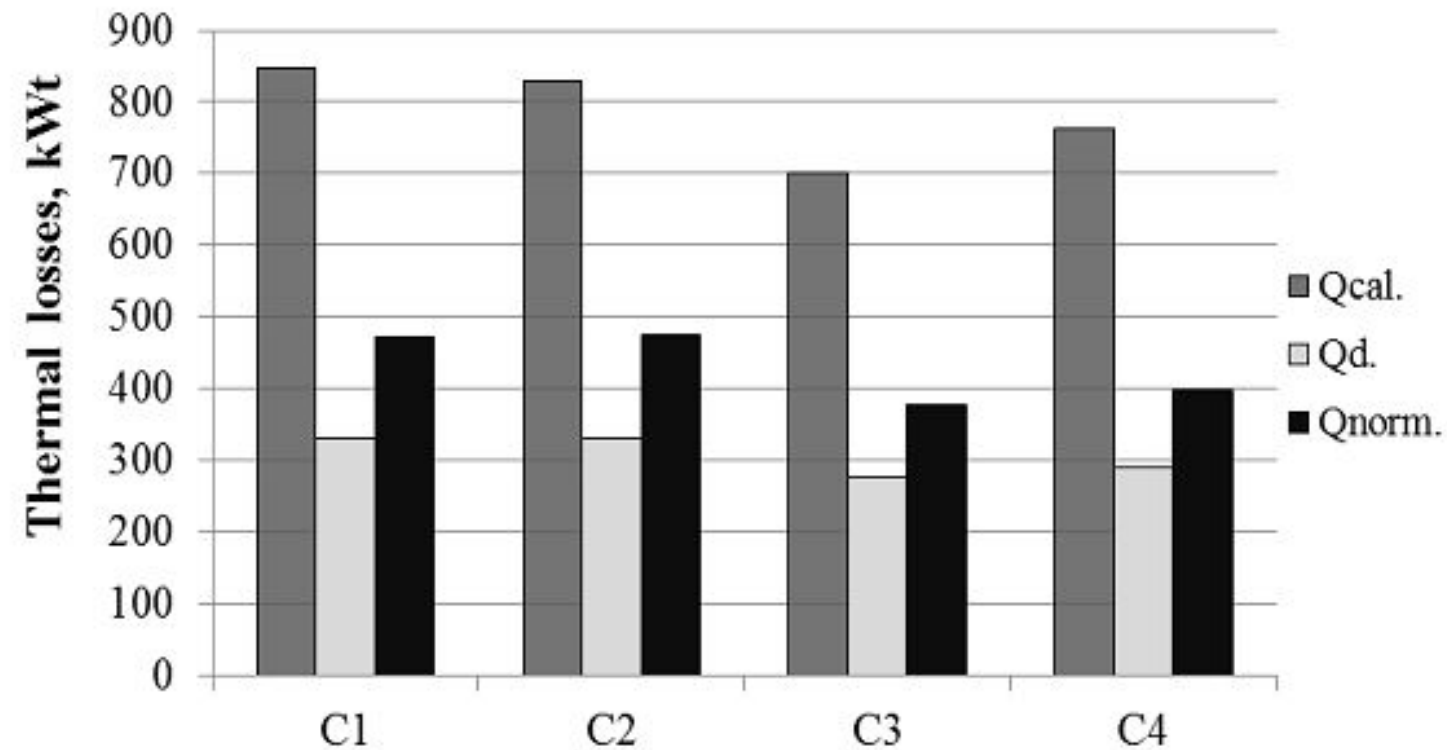

Figure 2. The results of definition of transport thermal losses: $\mathrm{Q}_{\mathrm{cal}}-$ calculated thermal losses, $\mathrm{Q}_{\mathrm{d}}-$ design thermal losses, $\mathrm{Q}_{\text {norm }}$ - normal thermal losses, C1 - C4 - heat consumers № 1-4.

From the received results (tab. 2, fig. 2) follows, that at the account of the operational factors influencing thermal resistance of mineral cotton wool, for all consumers the expected increase in the calculated thermal losses in comparison with design losses [2] is observed. Depending on size and the importance of factors, thermal losses can change in a wide range, in many exceeding design losses. For this case the calculated thermal losses on $150 \ldots 163 \%$ have exceeded design values. 
The received results confirm advantages of the offered approach [7] for definition of heat losses on each characteristic site of pipelines taking into account supernumerary conditions of operation and not standard technical condition of isolation in comparison with [2]. Together with modern ways of diagnostics of a condition of underground heat conductors [11] the offered method will allow to reveal sites with thermal losses above permitted standard, to prove necessity of carrying out of repair work, drainages of channels, an additional waterproofing. Operative reduction of the overestimated thermal losses to design level will allow to provide partial performance of the program of savings of power resources [1].

On the basis of results of tab. 2 it is possible to recommend application of a method [7] and a program complex [8] for more exact in comparison with [2], and also more operative and less expensive in comparison with [3] estimations of thermal losses in heat supply system.

\section{REFERENCES}

1. The federal law № 261 from November, 23rd, 2009 «About savings of power resources and about increase of power efficiency and about modification of separate acts of the Russian Federation».

2. The arch corrected № 41-103-2000 Designing of thermal isolation of the equipment and pipelines. M: Gosstroy Russia. - 2001.- 42 p.

3. Methodical instructions by definition of thermal losses in water thermal networks: RD 34.09.255-97. M.: SPO ORGRES, 1988.-18 p.

4. SNiP 23-01-99. Building a climate. - M: Publishing house of standards, 2004. - $70 \mathrm{p}$.

5. SNiP 41.03-2003. Thermal isolation of the equipment and pipelines. M.: Publishing house of standards, 2004.- $25 \mathrm{p}$.

6. Sokolov E.JA. Central heating and thermal networks: the textbook for high schools. - M: Publishing house of МЭИ, 2006.- $472 \mathrm{p}$.

7. Kyznetsov G.V., Ozerova I.P., Polovnikov V.Yu., Tsygankova Yu.S. Estimation of potential savings of power resources in system of transportation of thermal energy // Energetic.- 2012.- № 4.- P. 38 40.

8. Tsygankova Yu.S. Program complex by calculation of actual thermal losses and heat-carrier temperature drop on length of the pipeline working thermal networks // The certificate on the state registration of the computer program № 2011618250, 2011.

9. Tsygankova Yu.S., Kyznetsov G.V., Syutkin E.Yu. Analytical estimation of thermal losses as alternative to their measurement // Industrial power.- 2012.- № 8.- P. 9-17.

10. Methodical instructions on drawing up of the power characteristic for systems of transport of thermal energy on an indicator «thermal losses», part 3: RD 153-34.20.523-2003. M.: SPO ORGRES, 2003.- $28 \mathrm{p}$.

11. Timoshkin A.S. Devices for definition of a condition and places of damages of pipelines of thermal networks // Heat supply news.- 2001.- № 2.- P. 29 - 31.

Supervisor: Yu.S. Tsygankova, Ph.D., Senior Lecturer, Automation of heat power processes department, ENIN, TPU. 